\title{
An Analysis on the Types of Formulating Association Standards for General Drawing of Highway Engineering Design for Building Transportation Strength
}

\author{
Wei Zhao ${ }^{1}$, Yufei $\mathrm{Mao}^{2}$ and Dong Zhang ${ }^{1^{*}}$ \\ ${ }^{1}$ Research Institute of Highway Ministry of Transport, Beijing, 100088, China \\ ${ }^{2}$ Research Institute of Highway Ministry of Transport, Beijing, 100088, China
}

\begin{abstract}
This paper studies the classification of association standards of the general drawings of highway engineering design through investigation and analysis and sets up the system of the association standards. The classification management of general drawing standard system is carried out through research. The ten categories of general drawing management are proposed including general design, highway alignment, subgrade, pavement, bridge and culvert, tunnel, road intersection, traffic engineering and road facilities, environmental protection and landscape design, other engineering, road construction materials.
\end{abstract}

\section{Introduction}

\subsection{The Standardization Law of the People's Republic of China establishes the legal status of association standards}

The Third Plenary Session of the 18th Central Committee of the CPC made a decision to deepen the reform in an all-round way and vigorously foster and support social organizations to undertake various social functions. On March 11th,2015, the State Council issued the Plan of Furthering Standardization Work Reforms [1], marking the full start of China's standardization reform. The core of the Plan is to streamline the mandatory standards, optimize the voluntary standards, foster the development of association Standards. The Plan aims to foster and develop association standards as an important step in the standardization reform. The National Standardization System Construction and Development Plan (2016-2020) [2] calls for transforming the current standard system of the government's single-supply into a new standard system composed of government-led standards and market-determined standards. Social organizations such as associations of societies and chambers of commerce with corresponding abilities and industrial technical associations shall be encouraged to coordinate with relevant market entities to jointly formulate standards that meet the needs of the market and innovation, so as to provide them for the market to choose voluntarily and increase the effective supply of standards. On March 11th ,2016, the General Administration of Quality Supervision, Inspection and Quarantine of PRC and Standardization Administration issued the Guidance on Fostering and Developing Association Standards, stating that fostering and developing of association standards is an important measure to give play to the decisive role of the market in the standardized resource allocation and to speed up the construction of a new national standard system. On November 25th ,2016, the General Office of the Ministry of Housing, Urban-Rural Development of PRC issued an Opinion on Fostering and Developing Engineering Construction of Association Standards [3]. It requires the government to actively foster association standards, guide and encourage the use of association standards, create a good environment for the development of association standards, and clearly promote the transformation from the voluntary standards to association standards. The Standardization Law of the People's Republic of China [4], promulgated and implemented on January 1st ,2018, has established the legal status of association standards.

\subsection{The highway engineering construction urgently needs a batch of highway engineering design general drawing standards to guide the construction with high efficiency and high quality.}

Since the foundation of the People's Republic of China, the highway engineering has experienced nearly 60 years of development, especially the rapid development of motorways in the past 20 years. The highway industry has summarized and formed many sets of standard specifications in its continuous practice and development, covering the whole life cycle process of survey, design, construction, operation and maintenance, and a wide 
range of specialties with detailed divisions, including highway alignment, subgrades, bridge culverts, tunnels, greening, lighting, materials applications, etc., which has effectively supported highway construction. Along with the development of standardization in highway industry, each specialized design process has also carried out the standard drawing compilation work around the design drawing, so as to enhance the efficiency and universality of the drawing of design documents. In the design process, each design organization uses the standard drawing to conduct the design work, effectively promoted the design standardization and the design efficiency. The bridge culvert standard drawing and highway bridge standard drawing have been widely used, but the compilation of the standard drawing in highway industry has not been completely unified. At present, there is still no unified standard drawings supporting the design of highway slope protection engineering, which leads to the low legibility and standardization of the design drawings. Highway engineering construction belongs to national infrastructure construction. As a special service product, highway is an important embodiment of national economic and social development and is closely related to the public. How to make the highway serve the economy and society better, and to establish a perfect highway standardization system becomes an important guarantee. In 2013, the China Association for Engineering Construction Standardization held the First Summit Forum on Engineering Construction Standardization to adapt to the new situation, new tasks and new requirements of standardization work, the aim of engineering standardization is clear: to serve economy, society, government and standard users. The design of standard drawings has an irreplaceable role in promoting the progress of the industry, and can save the work of designers, and standardize the design of highway engineering.

Under the background and premise that China vigorously promotes the standardization work and requires the improvement of the standard system, it is of great significance to establish and develop association standard system for the design of general drawings of highway engineering construction sector to enrich and improve the standard system structure to meet the requirements of standards in the field of highway engineering and to guide the construction with high efficiency and high quality.

\section{The Purpose of Research}

The latest edition (2017 edition) of Standard System for Highway Engineering was published and implemented on January 1st,2018 by the Ministry of Transport of the People's Republic of China [5]. Most of the standards in the highway engineering standard system are technical standards and specifications, and there is a lack of general design drawings for reference in the highway engineering industry. In order to promote the development of high-standard and high-quality in the field of construction and enhance the design quality, the compilation of different types of general design drawings in the field of highway engineering is a supplement and improvement to the standard of standard system construction. Compared with the sector standard, the association standard has the quick and agile, small and intact characteristics. The general design drawing can be compiled in the form of catalogue in the association standard. When the time is appropriate, it can further apply for the sector standard and become the design standard to guide the highway sector. In order to strengthen the standard management of highway engineering, promote the technical progress and innovation of highway engineering, and improve the quality of highway engineering, it is urgent to compile the general engineering drawing.

The compilation of highway engineering standard drawing is an important part of the standardized design of engineering construction, an important basic work of highway engineering construction standardization, an important general technical document in the field of highway engineering construction, the summary and development of the achievements in various industries, the crystallization of advanced design ideas, the key factor to improve design efficiency, the necessary basis to guide standardized construction, which greatly improve the efficiency, reduce the management cost and standardize the construction of construction organizations, and improve maintenance efficiency of the management and maintenance organizations.

To sum up, in order to promote the overall level of technology in the field of highway engineering construction and the goal of building China's strength in transportation, it is of great significance to compile the sector standard and association standard of the general highway engineering design.

\section{Research contents}

\subsection{Investigate and summarize the sector standards drawings of Highway Engineering Construction}

The standard system is an important basis for compilation and revision of highway engineering standard drawings. The standard highway engineering system is divided into three layers:

The first layer is the plate, according to highway construction, management, maintenance, operation of coordinated development requirements of the standard classification. The second layer is a module, which summarizes the specific categories of existing, applicable and planned standards in each section. The third level is the standard. 
The standard system of highway engineering plays a guiding role in the standard general drawing system of highway engineering. It is composed of six parts: general, common-use, highway construction, highway management, highway maintenance and highway operation. Among them, the highway construction plate is the implementation of highway construction and reconstruction and expansion projects to follow the technical and management requirements.

The plate is the first-level classification of highway engineering standard system and is a standard set with its own system and inherent relevance. The current highway construction plate includes the project management, survey, design, test, detection, construction, supervision, cost and other components. Module is the second layer classification of highway engineering standard system, which is a unit with common features or interrelated elements to realize a certain function.

The project management module is used to guide the process management of highway construction project, which is composed of organization implementation, process supervision, assessment and evaluation.

The investigation module is used to guide highway survey and measurement, which is composed of highway investigation, engineering geological investigation, engineering hydrology, investigation design and other standards.

The design module is used to guide the design of new highway construction or reconstruction and expansion projects. It consists of design criteria such as alignment, subgrade, pavement, bridge and culvert, tunnel, traffic engineering and road facilities etc.

The test module is used to guide the indoor test of highway design, construction, maintenance and operation, it includes geotechnical test, geosynthetics test, rock test, aggregate test, binder test, asphalt and asphalt mixture test, cement and cement concrete test etc.

The detection module is used to guide the field detection of highway design, construction and operation, which is composed of the standard of subgrade and pavement field test, bridge field test, tunnel field test and electromechanical system field test.

The construction module is used to guide the construction work and management of highway new construction or reconstruction and expansion projects. It consists of subgrade, pavement, bridge and culvert, tunnel, traffic engineering and road facilities etc.

The supervision module is used to guide the supervision, management and consulting service of highway engineering construction.

The cost module is used to guide the determination and control of the cost in each stage of highway construction, such as project approval, construction and completion acceptance.

According to the classification system of highway engineering and the field survey data, the type system of the sector standard general drawing in the field of design is listed, which includes general design, alignment, subgrade, pavement, bridge, culvert, tunnel, road intersection, traffic engineering and road facilities, environmental protection and landscape design, other engineering, road construction materials.
At present, in the standard system of highway engineering, the design of construction plate is mostly standards and specifications and it is obvious that the standard of general drawing lacks. Many design organizations have compiled their own general drawing sets for internal use in enterprises according to production needs, but it has not become the association standard or the sector standard, which cannot lead the industry progress.

\subsection{The classification research and analysis of the system type of the sector standard general diagram in the design field}

Through extensive research and data collection, collation of standardization and highway design standards in the field of general diagram, the general diagram is divided into ten items: general design, general highway alignment, subgrade and pavement, bridge and culvert, tunnel, road intersection, traffic engineering and road facilities, environmental protection and landscape design, other engineering, road construction materials.

\subsubsection{General Design}

The general design includes highway alignment plan, vertical section, highway plan general design, highway standard cross section, etc.

\subsubsection{General highway alignment}

The general highway alignment includes highway alignment plan, vertical section plan, vertical curve table of vertical slope, general engineering geological plane plan, general engineering geological vertical section plan, bad geological table, safety facilities layout cross section plan, road survey concrete guardrail design plan, sign plane layout plan, etc.

\subsubsection{Subgrade and pavement}

The subgrade and pavement include general subgrade design drawing, subgrade standard cross-section drawing, high fill and deep dig subgrade design drawing, Bridgehead subgrade treatment design drawing, special subgrade design drawing, soil-collecting field waste residue field design drawing, subgrade protection engineering design drawing, pavement structure scheme drawing, subgrade and road surface drainage engineering design drawing.

\subsubsection{Bridge Culvert}

The bridge culvert includes water system diagram, bridge site plan, bridge site engineering geological plane diagram, bridge site engineering geological vertical section diagram, bridge type general layout diagram, scheme construction diagram, general layout of cover and culvert, general layout of pipe culvert etc. 


\subsubsection{Tunnel}

The tunnel consists of a tunnel geological plan and a tunnel geological profile, tunnel inner outline and building boundary scheme, tunnel entrance portal scheme, tunnel lining structure scheme, separate tunnel open tunnel waterproof drainage scheme, separate tunnel support scheme, tunnel waste disposal site layout scheme, tunnel composite pavement structure scheme, etc.

\subsubsection{Route intersection}

The route Intersection includes interchange plan, interchange vertical section, interchange effect, flyover layout, plane intersection layout, pipeline intersection layout, etc.

\subsubsection{Traffic engineering and road facilities}

The traffic engineering and road facilities includes route location plan, monitoring equipment layout plan, road organization plan, communication pipeline layout plan, underground access plan, high-voltage distribution system plan.

\subsubsection{Environmental Protection and Landscape Design:}

The environmental protection and landscape design include noise reduction design drawing, Slope Protection Landscape Design Drawing, central divider landscape design drawing, etc.

\subsubsection{Other engineering}

Other engineering works include road diversion plans, etc.

\subsubsection{The road-building materials}

The road-building materials includes the schematic diagram of material supply for road construction along the route

\subsection{The formation of standard system of general drawings for classification design}

According to the classification system of highway engineering and the field survey data, the type system of the sector standard general drawing in the field of design is listed, which includes general design, highway alignment, subgrade, pavement, bridge, culvert, tunnel, road intersection, traffic engineering and road facilities, environmental protection and landscape design, other engineering, road construction materials.

\section{Conclusion}

This study will further improve the standard system of highway engineering by compiling the system of the association standard of the general drawing of highway engineering design in building China's strength in transportation and guide the establishment of the general drawing of the missing association standard to promote the technological progress and innovation of highway engineering and the strategic needs of national transportation strength. As a standard top-level design in this field, it will provide direction guidance for the transformation of technological achievements and the development of dominant disciplines and make a good technical reserve for the standardization research work. It also provides important support in response to the development concepts of innovation, coordination, green, openness and sharing.

\section{References}

1. The State Council. (2015) Plan of Furthering Standardization Work Reforms. http://www.gov.cn/gongbao/content/2015/content_2 843769.htm

2. The State Council. (2015) The National Standardization System Construction and Development Plan. http://www.gov.cn/xinwen/201512/30/content_5029624.htm

3. The General Office of the Ministry of Housing, Urban-Rural Development of PRC. (2016) Opinion on Fostering and Developing Engineering Construction of Association Standards. http://www.mohurd.gov.cn/wjfb/201611/t20161124 229629.html

4. The State Council. (2017) The Standardization Law of the People's Republic of China. http://www.gov.cn/xinwen/201711/05/content_5237328.htm

5. The State Council. (2017) Standard System for Highway Engineering. http://www.gov.cn/xinwen/201711/29/content_5243122.htm 